Article

\title{
A Systematic Study on the Structural and Optical Properties of Vertically Aligned Zinc Oxide Nanorods Grown by High Pressure Assisted Pulsed Laser Deposition Technique
}

\author{
Priyanka Karnati ${ }^{1,2, *}$, Ariful Haque ${ }^{1,3}$, M. F. N. Taufique ${ }^{1,4}$ and Kartik Ghosh ${ }^{1}$ \\ 1 Department of Physics, Astronomy and Materials Science and Center for Applied Science and Engineering, \\ Missouri State University, Springfield, MO 65897, USA; ahaque@ncsu.edu or \\ ariful114@live.missouristate.edu (A.H.); m.taufique@wsu.edu (M.F.N.T.); \\ kartikghosh@missouristate.edu (K.G.) \\ 2 Department of Materials Science and Engineering, Ohio State University, Columbus, OH 43210, USA \\ 3 Department of Materials Science and Engineering, North Carolina State University, Raleigh, NC 27695, USA \\ 4 School of Mechanical and Materials Engineering, Washington State University, Pullman, WA 99163, USA \\ * Correspondence: karnati.3@buckeyemail.osu.edu or priyanka2@live.missouristate.edu
}

Received: 19 October 2017; Accepted: 27 November 2017; Published: 25 January 2018

\begin{abstract}
In this study, we synthesize high quality vertically aligned $\mathrm{ZnO}$ (VAZO) nanorods on silicon, sapphire, and indium tin oxide (ITO) substrates by using pulsed laser deposition (PLD) technique at high growth pressure (0.3 Torr). Systematic changes in structural and optical properties of VAZO nanorods are studied by varying the substrate temperature $\left(500-600^{\circ} \mathrm{C}\right)$ and number of pulsed laser shots during the deposition. $\mathrm{ZnO}$ nanoparticles deposited at high pressure act as nucleation sites, eliminating requirement of catalyst to fabricate VAZO nanorods. Two sharp ZnO peaks with high intensity correspond to the (0002) and (0004) planes in X-ray diffraction pattern confirm the growth of $\mathrm{ZnO}$ nanorods, oriented along the $c$-axis. Scanning Electron Microscopy (SEM) images indicate a regular arrangement of vertically aligned hexagonal closed pack nano-structures of $\mathrm{ZnO}$. The vertical alignment of $\mathrm{ZnO}$ nanorods is also supported by the presence of $\mathrm{E}_{2}$ (high) and $\mathrm{A}_{1}$ (LO) modes in Raman spectra. We can tune the diameter of VAZO nanorods by changing growth temperature and annealing environments. Photoluminescence spectroscopy illustrates reduction in defect level peak intensities with increase in diameter of VAZO nanorods. This study signifies that high pressure PLD technique can be used more efficiently for controlled and efficient growth of VAZO nanorods on different substrates.
\end{abstract}

Keywords: $\mathrm{ZnO}$ nanostructures; Raman spectroscopy; oxide semiconductors; optoelectronics; photoluminescence; defects; pulsed laser deposition

\section{Introduction}

$\mathrm{ZnO}$ has a direct band gap of $3.37 \mathrm{eV}$ and exciton binding energy of $60 \mathrm{meV}$ at room temperature, having device applications [1,2]. It is transparent in the visible wavelength range and has optoelectronic applications such as light emitting diodes (LEDs), transparent electrodes, and ultraviolet (UV) lasers [3,4]. ZnO nanostructures with different morphologies have drawn interest over the years, as having potential electronic applications and nano-structuring can improve performances of already existing devices by increasing the surface or interface area while maintaining the constant volume $[5,6]$. Vertically aligned zinc oxide (VAZO) nanorods are potentially useful for vertical device fabrication including light emitting diodes, solar cells, and nano piezoelectronics $[7,8]$. Numerous growth processes, such as chemical vapor deposition $[9,10]$ and various forms of physical vapor deposition 
techniques [11,12], have been used to synthesize VAZO nanorods in presence of a catalyst at high temperature and following a vapor-liquid-solid (VLS) mechanism. However, it has been a big challenge to find a controlled technique to grow well aligned $\mathrm{ZnO}$ nanorods. To gain control over the morphology, density, and the orientation of the grown nanostructures, the essential growth and processing steps of $\mathrm{ZnO}$ nanostructure formation need to be understood. In pulsed laser deposition (PLD) technique, nanostructure growth via vapor-solid (VS) mechanism can be initiated by the gas phase formation of nanoparticles at high pressures. The nanoparticles deposited on the substrate act as nucleation sites and promote nanostructure growth [13]. In general, VS-grown nanostructures are catalyst free and no additional steps are required for the removal of catalyst particles at the tips of the nanostructures in order to fabricate efficient devices. The dimensions of the grown nanostructures, however, depend only on the growth conditions and if employed on the nucleation layer. Therefore, the growth of nanostructures by the VS mechanism as well as their locations and densities are often more difficult to control than nanostructure formation by a catalyst. The present work involves growth of VAZO nanostructures without a catalyst, which follows VS growth mechanism. Annealing studies were performed to systematically analyze the properties of the VAZO nanorods. Different parameters such as influence of substrates, growth temperature, number of pulsed laser shots, and annealing temperature and environment-i.e., oxygen and forming gas (95\% Ar and 5\% $\left.\mathrm{H}_{2}\right)$-were considered to study the properties of VAZO nanorods. Moreover, the growth mechanism has been studied by varying the substrates, which plays a major role in the formation of the nanorods and also on the alignment. Varying the growth temperature and number of pulsed laser shots help to study the variation in diameter, length, and structural properties, such as crystallinity and defects, in the structure of the VAZO nanorods.

\section{Results}

\subsection{Scanning Electron Microscope (SEM) Analysis}

Figure 1a-c represent the field emission scanning electron microscope (FESEM) images of the $\mathrm{ZnO}$ nanorods on silicon, sapphire, and indium tin oxide (ITO) substrates. Wurtzite structure of $\mathrm{ZnO}$ can be confirmed from the FESEM images and the diameter of 1D nanostructure was measured to be in between 300-500 $\mathrm{nm}$. The vertical alignment of these nanorods is high when grown on the silicon substrate, which mainly depends on the growth mechanism and surface energy of the Si substrate [14]. Figure 1d-f represents the SEM images of the VAZO nanorods grown on Si substrate at different temperatures $\left(500,550\right.$, and $\left.600{ }^{\circ} \mathrm{C}\right)$. The variation in the diameter of these nanorods is evident and ranging from 50-500 $\mathrm{nm}$ were calculated by using ImageJ software. The increase in the substrate temperature resulted in an increase in the diameter of the rods, which is mainly dependent on the growth mechanism and stress between the substrate and nanorods formed [15]. From the SEM images in Figure $1 \mathrm{~g}-\mathrm{i}$, we observe an increase in length of the nanorods, varying from $400 \mathrm{~nm}^{-1} \mu \mathrm{m}$, with increasing number of pulsed laser shots. From these SEM images, it is also evident that the nanorods tend to bend as the number of pulsed laser shots increases, which mainly depends on the stability of the nanorods [16]. The diameter and length of the nanorods has been varied as we change the process parameters. The average diameter and length of the nanorods are shown in Table 1.

Table 1. Average diameter and lengths of VAZO nanorods grown by PLD technique.

\begin{tabular}{cccccccc}
\hline $\begin{array}{c}\text { Serial } \\
\text { No. }\end{array}$ & $\begin{array}{c}\text { Number } \\
\text { of Shots }\end{array}$ & Temperature & $\begin{array}{c}\text { Average } \\
\text { Diameter } \\
\text { of the } \\
\text { Nanorods }\end{array}$ & $\begin{array}{c}\text { Average } \\
\text { Length of the } \\
\text { Nanorods }\end{array}$ & $\begin{array}{c}\text { Standard } \\
\text { Deviation } \\
\text { (Diameter of } \\
\text { Nanorods) }\end{array}$ & $\begin{array}{c}\text { Standard } \\
\text { Deviation } \\
\text { (Length of } \\
\text { Nanorods) }\end{array}$ & $\begin{array}{c}\text { Average } \\
\text { Aspect } \\
\text { Ratio }\end{array}$ \\
\hline 1 & 5000 & $500^{\circ} \mathrm{C}$ & $79 \mathrm{~nm}$ & $286 \mathrm{~nm}$ & $2.5 \mathrm{~nm}$ & $2.35 \mathrm{~nm}$ & 3.43 \\
2 & 5000 & $550^{\circ} \mathrm{C}$ & $185 \mathrm{~nm}$ & $900 \mathrm{~nm}$ & $2.6 \mathrm{~nm}$ & $0.57 \mu \mathrm{m}$ & 8.44 \\
3 & 10,000 & $550^{\circ} \mathrm{C}$ & $162 \mathrm{~nm}$ & $1 \mu \mathrm{m}$ & $1.6 \mathrm{~nm}$ & $0.36 \mu \mathrm{m}$ & 7.72 \\
\hline
\end{tabular}



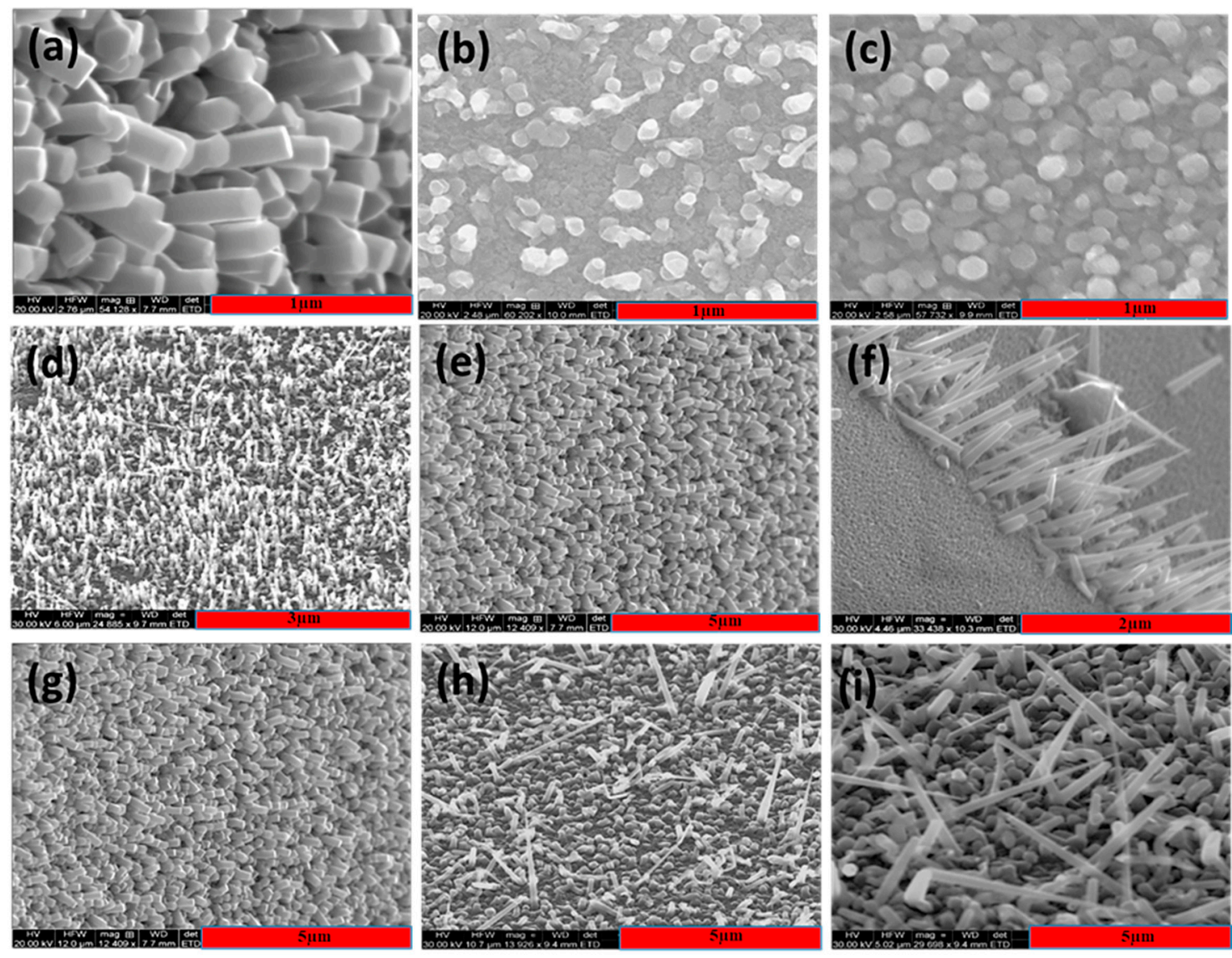

Figure 1. SEM Images of $\mathrm{ZnO}$ nanorods (a) Vertically aligned on silicon substrate $\left(60^{\circ}\right.$ titled view); (b) Sapphire substrate (top view); (c) Indium tin oxide (ITO) substrate (top view), SEM images of vertically aligned $\mathrm{ZnO}$ nano rods (5000 shots) grown at different temperatures on silicon substrate $\left(60^{\circ}\right.$ titled view) (d) $500{ }^{\circ} \mathrm{C}$, (e) $550{ }^{\circ} \mathrm{C}$, (f) $600{ }^{\circ} \mathrm{C}$ and SEM images of the $\mathrm{ZnO}$ nanorods by varying the number of pulsed laser shots at $550{ }^{\circ} \mathrm{C}$ temperature (g) 5000, (h) 10,000, and (i) 15,000.

\subsection{X-Ray Diffraction Analysis (XRD)}

Figure 2a-c represent the X-ray diffraction pattern of $\mathrm{ZnO}$ nanorods on $\mathrm{Si}$ substrate. In addition to the substrate peak, VAZO nanostructures show strong peaks corresponding to (0002) and (0004) planes. The strong peak associated with (0002) plane implies that the $\mathrm{ZnO}$ nanostructures were preferentially oriented along the $c$-axis [17]. The preferred orientation of $\mathrm{ZnO}$ nanostructures along (0002) also indicates that the as grown nanostructures have good epitaxial orientation with the Si substrate, which can also be verified through SEM images shown previously. From Figure 2a,b it is evident that the nanorods deposited at $500{ }^{\circ} \mathrm{C}$ and $550{ }^{\circ} \mathrm{C}$ are preferentially oriented along the (0002) plane.

Figure $2 \mathrm{c}$ represents the XRD pattern of sample deposited at $600{ }^{\circ} \mathrm{C}$ confirming the presence of other $\mathrm{ZnO}$ planes. This implies that the orientation of $\mathrm{ZnO}$ nanorods has been changed with increasing deposition temperature in the PLD system. Figure $2 \mathrm{~d}-\mathrm{f}$ represents the XRD spectrum of $\mathrm{ZnO}$ samples grown by varying the number of pulsed laser shots from 5000 to 15,000 at $550{ }^{\circ} \mathrm{C}$. The increased number of pulsed laser shots led to the formation of bulk $\mathrm{ZnO}$, which is confirmed through XRD pattern. Full Width Half Maxima (FWHM) of (0002) plane of ZnO samples has been calculated by using Labspec 5 software, which helps in determining the crystallinity in the samples. R. R. Reeber measured lattice constants of $\mathrm{ZnO}$ wurtzite structure at room temperature, values of $c$, a being $5.2075 \AA, 3.25 \AA$, respectively, and resulting $\frac{c}{a}$ ratio 1.633 [18]. Measured FWHM value of (0002) plane, interplanar spacing $(d)$, lattice parameters ( $c$ and $a$ ), and the $\frac{c}{a}$ ratio calculated for $\mathrm{ZnO}$ nanorod samples deposited on Si substrate are shown in Table 2. 

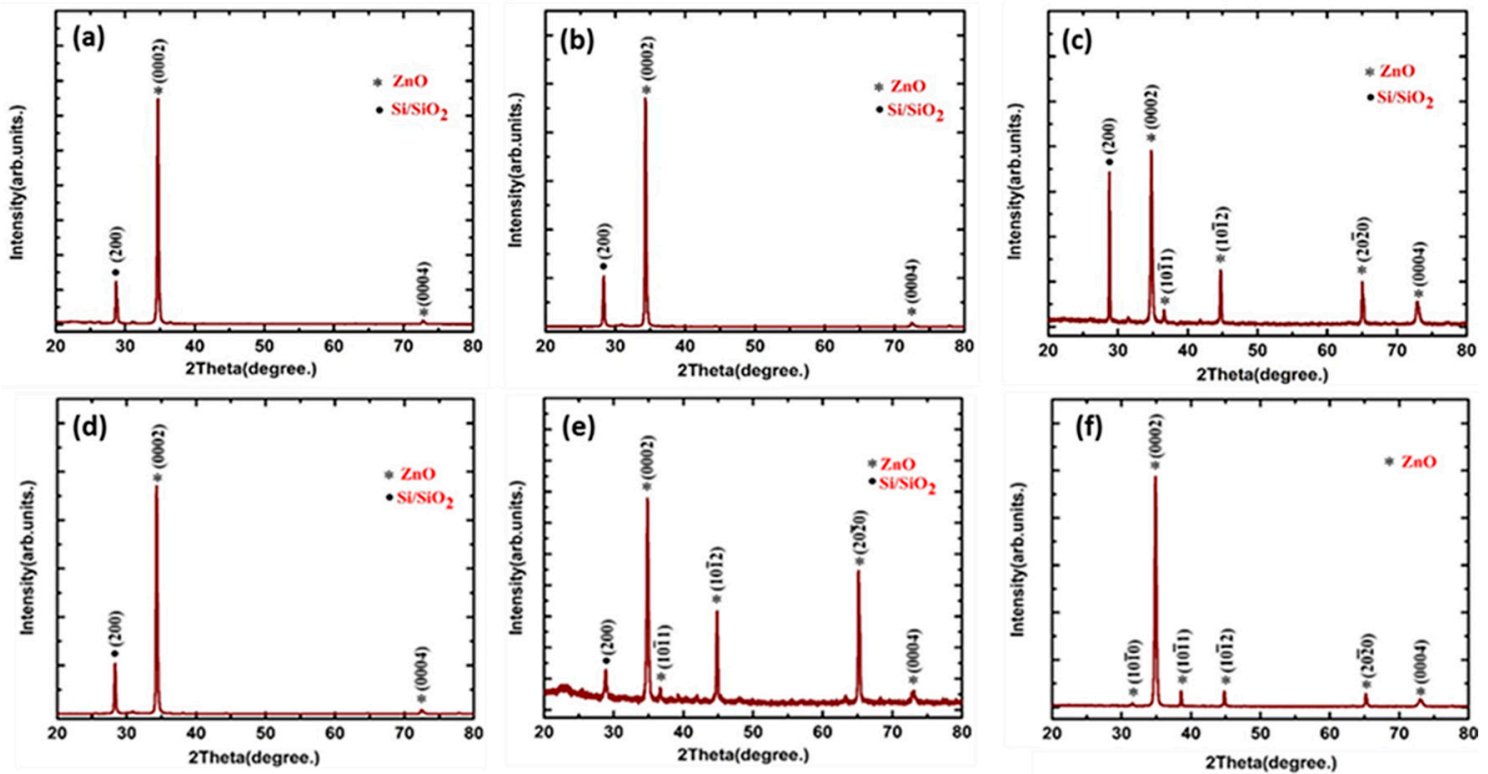

Figure 2. XRD spectrum of VAZO nanorods grown on Si substrate at (a) $500{ }^{\circ} \mathrm{C},(\mathbf{b}) 550{ }^{\circ} \mathrm{C},(\mathbf{c}) 600{ }^{\circ} \mathrm{C}$ and XRD spectrum of VAZO nanorods grown on Si substrate at $550{ }^{\circ} \mathrm{C}$ by varying the number of shots (d) 5000, (e) 10,000, (f) 15,000.

The following formula was used for calculating the lattice parameters.

$$
\frac{1}{d^{2}}=\frac{4}{3}\left(\frac{h^{2}+h k+l^{2}}{a^{2}}\right)+\frac{l^{2}}{c^{2}}
$$

Table 2. XRD Peak positions of (0002) plane of $\mathrm{ZnO}$ nanorods deposited on Si substrate.

\begin{tabular}{cccccccc}
\hline $\begin{array}{c}\text { Serial } \\
\text { No. }\end{array}$ & $\begin{array}{c}\text { Number of Pulsed } \\
\text { Laser Shots }\end{array}$ & $\begin{array}{c}\text { Temperature } \\
\left({ }^{\circ} \mathbf{C}\right)\end{array}$ & $\begin{array}{c}\text { FWHM } \\
\text { (Degree) (0002) }\end{array}$ & $\begin{array}{c}\text { Interplanar } \\
\text { Spacing (d) }(\AA)\end{array}$ & $\boldsymbol{c}(\AA)$ & $\boldsymbol{a}(\AA)$ & $\frac{c}{a}$ \\
\hline 1 & 5000 & 500 & 0.268 & 2.583 & 5.166 & 3.31 & 1.56 \\
2 & 5000 & 550 & 0.268 & 2.612 & 5.224 & 3.23 & 1.61 \\
3 & 10,000 & 550 & 0.258 & 2.572 & 5.144 & 3.22 & 1.59 \\
4 & 15,000 & 550 & 0.287 & 2.570 & 5.140 & 3.11 & 1.65 \\
5 & 5000 & 600 & 0.242 & 2.577 & 5.154 & 3.22 & 1.60 \\
\hline
\end{tabular}

\subsection{Raman Spectra Analysis}

Figure $3 \mathrm{a}-\mathrm{c}$ represents the Raman spectra of the VAZO nanorods grown on Si substrates at different temperatures. Wurtzite $\mathrm{ZnO}$ belongs to $C_{6 v}^{4}\left(P \sigma_{3} m c\right)$ space group. The primitive cell includes two formula units with all atoms occupying $2 b$ sites of symmetry. According to group theory, wurtzite $\mathrm{ZnO}$ structure is expected to have $\mathrm{A}_{1}(z)+2 \mathrm{~B}_{1}+\mathrm{E}_{1}(x, y)+2 \mathrm{E}_{2}$ optical phonon modes at the $\Gamma$ point of the Brillouin zone [19]. As a result, $A_{1}$ and $E_{1}$ phonon modes are infrared and Raman active. Raman modes that can be observed in the spectrum mainly depend on the Raman selection rules and geometry employed to attain the spectra. Backscattering (z) geometry was used to perform the Raman spectroscopy. The $c$-axis of wurtzite $\mathrm{ZnO}$ structure is along the $z$ direction, hence, Raman peaks of $\mathrm{A}_{1}$ (LO) and $\mathrm{E}_{2}$ (high) are allowed according to Raman selection rules [20]. Raman spectra of different $\mathrm{ZnO}$ nanorod samples shown in Figure 3 confirm the presence of $\mathrm{E}_{2}$ high mode. The peak position and FWHM of the Raman $\mathrm{E}_{2}$ high mode of the $\mathrm{ZnO}$ nanorods were determined by LabSpec 5 software using Lorentzian function. The position of $E_{2}$ high peak varies from $436.16 \mathrm{~cm}^{-1}$ to $436.24 \mathrm{~cm}^{-1}$ for samples grown at $500{ }^{\circ} \mathrm{C}$ and $550{ }^{\circ} \mathrm{C}$, respectively. Since $\mathrm{E}_{2}$ high mode is more sensitive to stress, compressive 
stresses are responsible for the shift to a higher value [21] when the deposition temperature is increased leading to increase in diameter of VAZO nanorods. The presence of quasi modes can also be seen in the Raman spectra of Figure 3b, which is dependent on bending and alignment of the rods [22]. The amount of stress developed in the VAZO nanorod samples is less compared to the $\mathrm{ZnO}$ thin films, which may be due to the relaxation effect of the $\mathrm{ZnO}$ nanorods. Figure $3 \mathrm{~d}-\mathrm{f}$ represents the Raman spectra of $\mathrm{ZnO}$ nanorod samples grown at $550{ }^{\circ} \mathrm{C}$ with varying number of pulsed laser shots from 5000 to 15,000 . The FWHM of the $\mathrm{E}_{2}$ high phonon mode changes with increasing number of pulsed laser shots. This is due to the dependence of the FWHM of this peak on the crystallinity of ZnO nanorods. FWHM of the $\mathrm{ZnO}$ sample grown by 15,000 pulsed laser shots increases and peak position matches with that of $\mathrm{ZnO}$ thin film. $\mathrm{A}_{1}$ (LO) mode can only be seen in Raman spectra of aligned $\mathrm{ZnO}$ nanorod samples as per Raman selection rules [23]. Figure $4 a, b$ represent $A_{1}(L O)$ mode present in aligned $\mathrm{ZnO}$ nanorod samples. This mode has only been seen in samples grown at $500{ }^{\circ} \mathrm{C}$ and $550{ }^{\circ} \mathrm{C}$ and alignment of $\mathrm{ZnO}$ nanorods can be verified through high resolution SEM images. The peak positions of $\mathrm{E}_{2}$ high phonon mode are represented in Table 3 .

Annealing experiments were performed in both oxygen and hydrogen medium at $500{ }^{\circ} \mathrm{C}$ for the $\mathrm{ZnO}$ sample grown at the same temperature on Si substrate. A pressure of 0.3 mbar was maintained during the annealing process. Figure 4c,d represents Raman spectra of samples annealed in oxygen and hydrogen environments, respectively. A red shift in $\mathrm{E}_{2}$ high phonon mode was observed when compared to the peak position of $\mathrm{E}_{2}$ high phonon mode of $\mathrm{ZnO}$ nanorods sample before annealing. The peak position of $\mathrm{E}_{2}$ high phonon mode for samples annealed in oxygen atmosphere and hydrogen atmosphere were found to be at $431.36 \mathrm{~cm}^{-1}$ and $431.05 \mathrm{~cm}^{-1}$, respectively. Peak positions in both samples are in coherence with $\mathrm{ZnO}$ thin film, which implies that the alignment of the $\mathrm{ZnO}$ nanorods has been changed. A decrease in the FWHM of this peak was observed after the annealing treatment. It can also be inferred that a sharper $\mathrm{E}_{2}$ high mode signifies a greater crystallinity of $\mathrm{ZnO}$ nanorods. Crystallinity of $\mathrm{ZnO}$ nanorod samples can also be confirmed from photoluminescence studies by observing the change in defect levels.
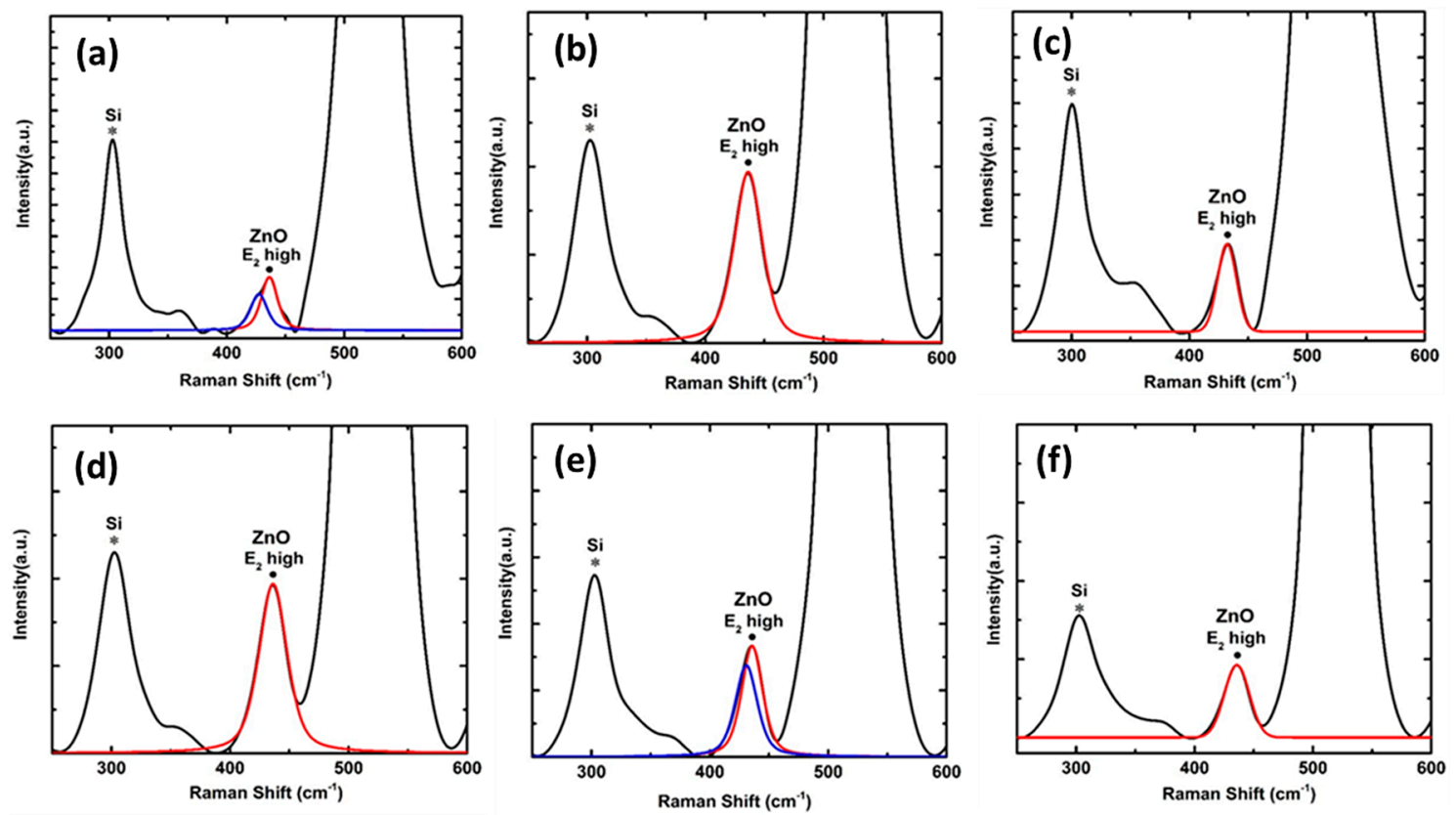

Figure 3. Raman spectra of $\mathrm{ZnO}$ nanorods at different temperatures (a) $500{ }^{\circ} \mathrm{C}$, (b) $550{ }^{\circ} \mathrm{C}$, (c) $600{ }^{\circ} \mathrm{C}$ and Raman spectra of $\mathrm{ZnO}$ nanorods grown at $550^{\circ} \mathrm{C}$ by varying the number of pulsed laser shots (d) 5000, (e) 10,000, (f) 15,000. 

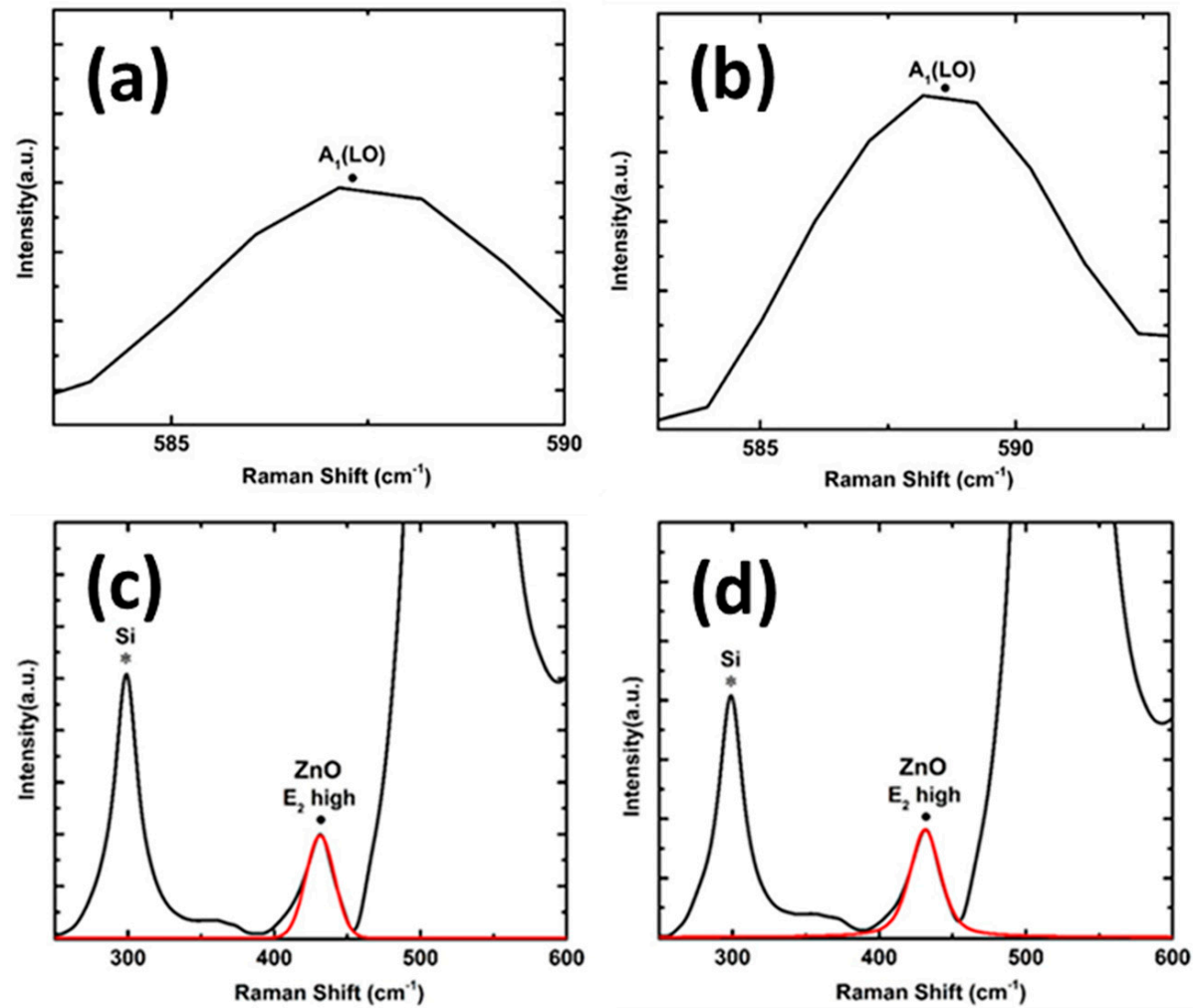

Figure 4. $\mathrm{A}_{1}$ (LO) mode in Raman spectra of aligned $\mathrm{ZnO}$ nanorods at (a) $500{ }^{\circ} \mathrm{C}$ (b) $550{ }^{\circ} \mathrm{C}$ and $\mathrm{E}_{2}$ high mode of aligned $\mathrm{ZnO}$ nanorods grown at $500{ }^{\circ} \mathrm{C}$, annealed in (c) $\mathrm{O}_{2}$ atmosphere (d) $\mathrm{H}_{2}$ atmosphere.

Table 3. Raman peak $E_{2}$ high mode positions of VAZO nanorods.

\begin{tabular}{|c|c|c|c|c|}
\hline Serial. No & Number of Shots & Temperature $\left({ }^{\circ} \mathrm{C}\right)$ & $\begin{array}{l}\mathrm{E}_{2} \text { High }\left(\mathrm{cm}^{-1}\right) \\
\text { (Peak Position) }\end{array}$ & $\begin{array}{c}\mathrm{E}_{2} \underset{\mathrm{High}\left(\mathrm{cm}^{-1}\right)}{\text { (FWHM) }} \\
\text { (FWHM }\end{array}$ \\
\hline 1 & 5000 & 500 & 436.1 & 16.5 \\
\hline 2 & 5000 & 550 & 436.2 & 28.1 \\
\hline 3 & 10,000 & 550 & 435.7 & 21.1 \\
\hline 4 & 15,000 & 550 & 435.7 & 24.6 \\
\hline 5 & 5000 & 600 & 431.94 & 18.8 \\
\hline 6 & 5000 (annealed in $\mathrm{O}_{2}$ ) & 500 & 431.36 & 22.9 \\
\hline 7 & 5000 (annealed in $\mathrm{H}_{2}$ ) & 500 & 431.05 & 24.6 \\
\hline
\end{tabular}

\subsection{Photoluminescence (PL) Spectra Analysis}

Optical properties of the VAZO nanorods were investigated by performing the PL spectroscopy. Figure $5 \mathrm{a}-\mathrm{c}$ represents PL spectra of $\mathrm{ZnO}$ nanorods at temperatures 500, 550, and $600{ }^{\circ} \mathrm{C}$, respectively. All PL spectra show a luminescence emission in-between $3.23 \mathrm{eV}$ and $3.24 \mathrm{eV}$, which is due to direct recombination of the excitons [24]. Appearance of one UV peak for nanorods is an indication of uniform distribution of the rod size [25]. ZnO samples in Figure 5a,c grown at $500{ }^{\circ} \mathrm{C}$ and $600{ }^{\circ} \mathrm{C}$, respectively, show a wide and strong deep level emission around $2.08 \mathrm{eV}$. This orange emission has been found in oxygen rich $\mathrm{ZnO}$ films grown by PLD process and is attributed to oxygen interstitial defects $[26,27]$. ZnO samples were grown in highly oxygen rich atmosphere and at high temperature; hence, there is a possibility for the formation of oxygen interstitials in the structures. In the $\mathrm{ZnO}$ sample grown at $550{ }^{\circ} \mathrm{C}$, a shift in the deep-level green emission at $\sim 2.23 \mathrm{eV}$ has been observed as shown in Figure $5 \mathrm{~b}$. This occurs due to the structural defects such as oxygen vacancies or zinc interstitials [28]. With increase in growth temperature from $500{ }^{\circ} \mathrm{C}$ to $600^{\circ} \mathrm{C}$, an increase in size of the VAZO nanorods was observed from SEM image analysis. For $\mathrm{ZnO}$ nanostructures the effect of surface status on the PL 
intensity must be carefully considered [29]. Band bending creates an electron depletion layer around the $\mathrm{ZnO}$ rod surface, which is more than $100 \mathrm{~nm}$. This layer plays a key role as the photoemissions occur deep from the surface [30]. Therefore, as the $\mathrm{ZnO}$ nanorods diameter is increasing, where the depletion layer is not so important, the oxygen vacancies lead to stronger green emission compared to the nanorods with smaller diameter reducing the green emission intensity [11]. With an increase in the growth temperature $\left(600{ }^{\circ} \mathrm{C}\right)$, in case of Figure $5 c$, we can see a decrease in deep level emission intensity because of the improved crystallinity in the sample.
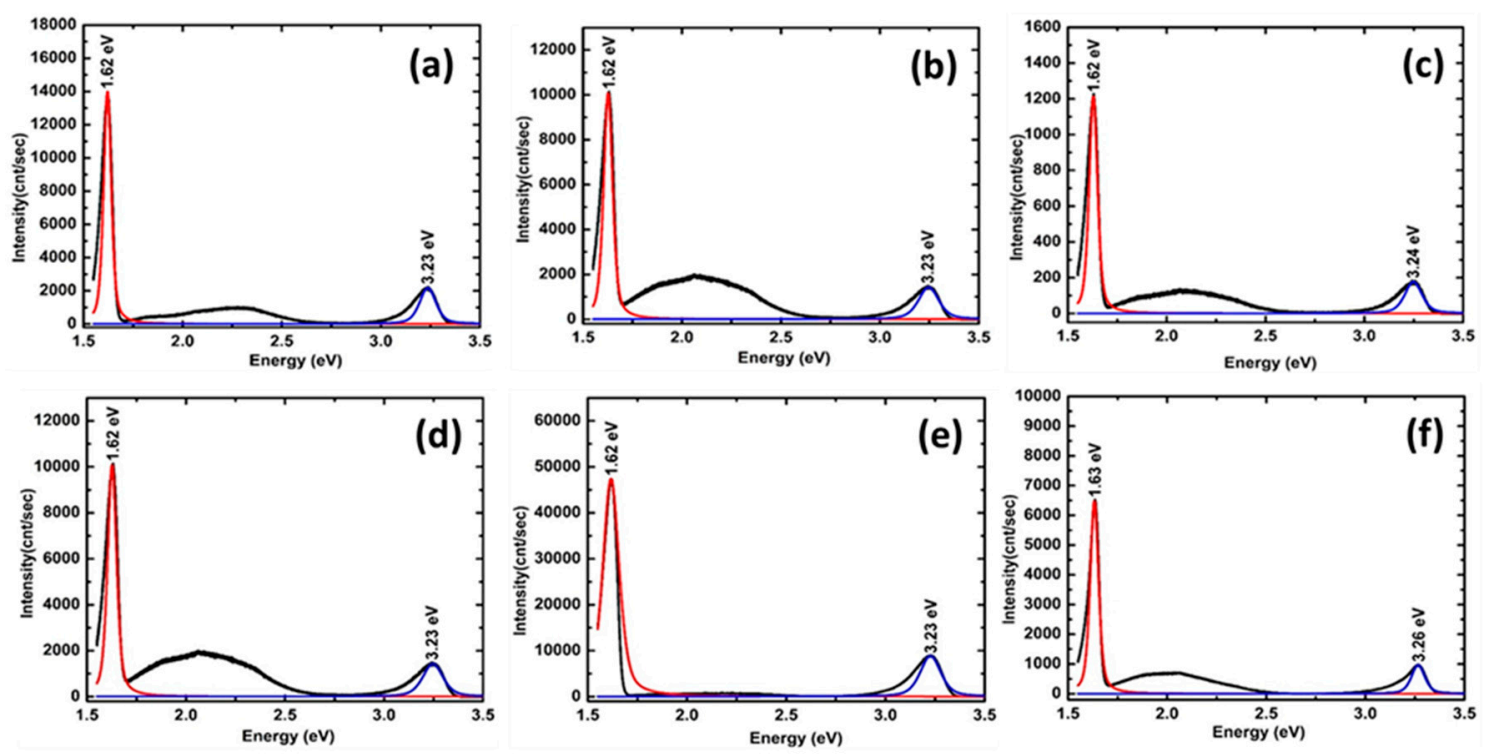

Figure 5. PL spectra of $\mathrm{ZnO}$ nanorods grown by using 5000 pulsed laser shots at different temperatures (a) $500{ }^{\circ} \mathrm{C}$, (b) $550{ }^{\circ} \mathrm{C}$, (c) $600{ }^{\circ} \mathrm{C}$ and PL spectra of $\mathrm{ZnO}$ nanorods grown at $550{ }^{\circ} \mathrm{C}$ by varying the number of pulse laser shots (d) 5000, (e) 10,000, (f) 15,000.

Figure 5d-f represents PL spectra of ZnO nanorods samples grown by 5000, 10,000 and 15,000 pulsed laser shots, respectively. Length of $\mathrm{ZnO}$ nanorods has been increased with the number of pulsed laser shots, which was verified from SEM images. A reduction in the green emission level intensity was observed in Figure 5e compared to that in Figure 5d. When the number of pulsed laser shots during the deposition was increased to 15,000, bending of rods can be seen and the tendency to form thin films is evident from SEM image. The tendency to form thin film can be seen in the presence of orange-red defect level, which is mainly due to the presence of oxygen interstitials. This defect level is visible in the PL spectra presented in Figure 5f. To confirm the origin of defect peaks from the PL analysis, VAZO nanorods grown at $500{ }^{\circ} \mathrm{C}$ were annealed in both oxidizing and reducing atmosphere. After annealing for $30 \mathrm{~min}$ in oxygen atmosphere at $500{ }^{\circ} \mathrm{C}$, the defect peak intensity related to the oxygen interstitial is reduced, which can be observed from Figure 6a. Improved crystallinity of VAZO nanorods can be confirmed after annealing in oxygen atmosphere. Reduced oxygen interstitial concentration can be attributed to oxygen desorption from $\mathrm{ZnO}$ nanorod structure, which occurs due to the annealing at high temperature $\left(500^{\circ} \mathrm{C}\right)$ [31]. Similarly, annealing of $\mathrm{ZnO}$ nanorods was carried out in reducing environment $\left(\mathrm{H}_{2}\right)$ at $500{ }^{\circ} \mathrm{C}$ and the associated PL spectrum is shown in Figure $5 \mathrm{~b}$. Reduction of peak intensity of oxygen interstitials was observed in PL spectra. Due to large surface area and small diameter of $\mathrm{ZnO}$ nanorods, hydrogen diffuses readily into the crystal rods to further reduce oxygen present in $\mathrm{ZnO}$ crystal, thus reducing the oxygen interstitials [32]. The shift in defect peaks by changing the process parameters has been listed in the Table 4 . 

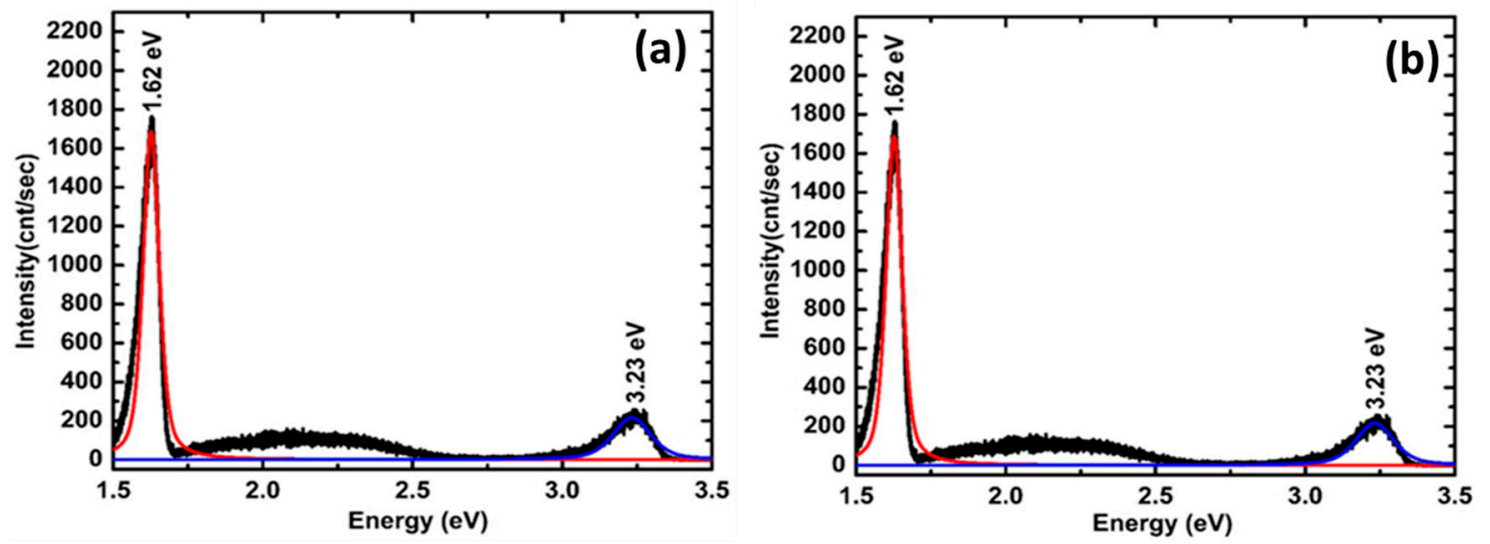

Figure 6. $\mathrm{PL}$ spectra of $\mathrm{ZnO}$ nanorods grown at $500{ }^{\circ} \mathrm{C}$ and annealed in (a) $\mathrm{O}_{2}$ atmosphere (b) $\mathrm{H}_{2}$ atmosphere.

Table 4. Defect peak positions of VAZO nanorods from PL spectra.

\begin{tabular}{cccc}
\hline Serial. No & Number of Shots & Temperature $\left({ }^{\circ} \mathbf{C}\right)$ & Defect Peak Position $(\mathbf{e V})$ \\
\hline 1 & 5000 & 500 & 2.08 \\
2 & 5000 & 550 & 2.23 \\
3 & 10,000 & 550 & 2.18 \\
4 & 15,000 & 550 & 2.01 \\
5 & 5000 & 600 & 2.08 \\
6 & $5000\left(\right.$ annealed in $\left.\mathrm{O}_{2}\right)$ & 500 & 2.13 \\
7 & $5000\left(\right.$ annealed in $\left.\mathrm{H}_{2}\right)$ & 500 & 2.14 \\
\hline
\end{tabular}

\section{Discussion}

Several parameters are responsible for the change in alignment, structural and optical properties of $\mathrm{ZnO}$ nanorods grown by PLD technique. Among these substrate types, growth temperature, number of pulsed laser shots, and annealing environment play important roles. XRD analysis explains about the crystallinity and the preferred orientation of the $\mathrm{ZnO}$ nanorods, which is not sufficient to confirm the vertical alignment of the rods. SEM and Raman analysis help to verify the vertical alignment of $\mathrm{ZnO}$ nanorods. SEM analysis helps in determining the average length and diameter of the $\mathrm{ZnO}$ nanorods. The diameter varies from $50 \mathrm{~nm}$ to $500 \mathrm{~nm}$ as the growth parameters are changed. Vertical alignment is visible from SEM images. The presence of $\mathrm{E}_{2}$ high and $\mathrm{A}_{1}(\mathrm{LO})$ modes in Raman spectra also supports this. Alignment is also dependent on the substrate used, which follows Volmer-Weber model for formation of the $\mathrm{ZnO}$ nanorods. Growth of $\mathrm{ZnO}$ nanorods follows VS mechanism, i.e., formation of the nanorods without a catalyst through PLD technique.

$\mathrm{ZnO}$ nanoparticles ablated from the target at high pressure act as nucleation sites and help in the formation of nanorods. Alignment of $\mathrm{ZnO}$ nanorods, which mainly depends on surface energies, was found to be more efficient on Si substrate. Smaller FWHM of the $E_{2}$ high phonon mode signifies better alignment of the $\mathrm{ZnO}$ nanorods. Change in growth temperature during the pulsed laser deposition of $\mathrm{ZnO}$ samples helped in determining apt parameters for fabricating VAZO nanorods with desirable properties. An increase in the diameter of $\mathrm{ZnO}$ nanorods was observed as the temperature was increased, which is evident from the SEM analysis and form the shift in $\mathrm{E}_{2}$ high mode in Raman spectroscopy. The change in defect levels was seen in PL spectra due to increase in diameter of VAZO nanorods. Band bending and formation of the depletion layer played key roles in shift of defect levels of VAZO nanorods. A change in length of the rods was detected from SEM images as the number of pulsed laser shots was changed. As the number of laser shots was increased from 5000 to 15,000, a shift in $\mathrm{E}_{2}$ high mode was detected and absence of $\mathrm{A}_{1}(\mathrm{LO})$ mode, which mainly explains about the vertical alignment of the $\mathrm{ZnO}$ nanorods, was observed. In PL spectra, a change in UV band emission 
has been observed for $\mathrm{ZnO}$ nanorods sample grown at 15,000 shots, which coincides with bulk $\mathrm{ZnO}$. The reduced intensity of defect levels also explains the crystallinity of the $\mathrm{ZnO}$ sample.

Annealing treatment was performed to analyze the defect levels of VAZO nanorods in both oxidizing and reducing atmosphere. Annealing in the presence of oxygen atmosphere led to a decrease in intensity of defect level as seen in PL spectra and a shift in $E_{2}$ high Raman mode. Absence of $A_{1}$ (LO) phonon mode and peak position of $\mathrm{E}_{2}$ high mode coincides with the bulk $\mathrm{ZnO}$, which proves that the alignment of nanorods has been changed. Decreased intensity of the defect levels associated with the oxygen interstitials can also be attributed to the temperature $\left(500^{\circ} \mathrm{C}\right)$ used during the annealing treatment, which helped the oxygen atoms to move away from the $\mathrm{ZnO}$ wurtzite structure. Annealing in the presence of reducing atmosphere led to reduced intensity of the defect levels. Large surface area and smaller diameter of VAZO rods might help hydrogen atoms to diffuse easily through the surface and reduce the oxygen interstitials present in the structure. A shift in the Raman mode is also observed, which signifies better alignment of the $\mathrm{ZnO}$ nanorods. Figure 7 represents Pulse laser deposition (PLD) setup used for synthesis of vertically aligned $\mathrm{ZnO}$ nanorods. Figure 8 represents the schematic diagram of growth of VAZO nano rods starting from the deposition of $\mathrm{ZnO}$ nanoparticles during initial stage, and then formation of VAZO nanorods after entire deposition process. Bending of the VAZO nanorods has also been shown as we increase in number of pulsed laser shots.

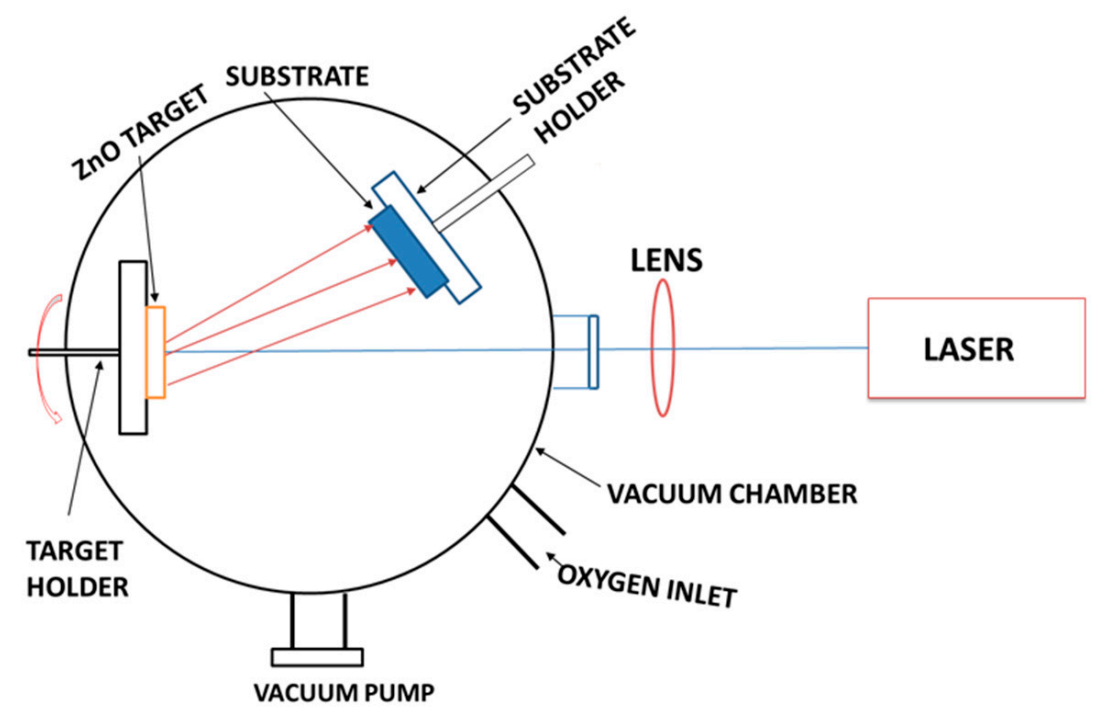

Figure 7. Pulsed laser deposition (PLD) setup used for synthesis of vertically aligned ZnO nanorods (VAZO).

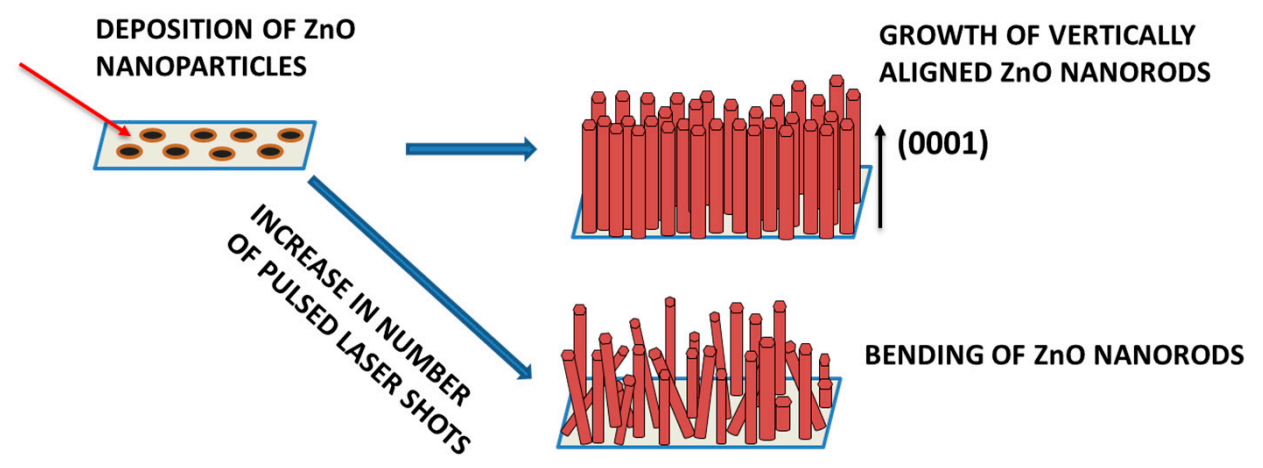

Figure 8. Schematic diagram of growth of vertically aligned $\mathrm{ZnO}$ nanorods (VAZO) by using high pressure assisted pulse laser deposition (PLD) process. 


\section{Materials and Methods}

VAZO nanorods were synthesized from a highly dense and pure ZnO target by using PLD technique (Excel Instrument, PLD-STD-18). Laser source used was Lambda Physik, COMPEX201 high energy UV KrF excimer laser. The fabricated nanorods were grown at an average laser energy density in between 3-4 J/ $\mathrm{cm}^{2}$. During the deposition process, the pulsed laser frequency was maintained at $10 \mathrm{~Hz}$ with a pulse duration of $20 \mathrm{~ns}$. The laser was focused on to a $1.9 \mathrm{~cm}$ diameter $\mathrm{ZnO}$ target prepared by $99.9 \%$ pure micron sized $\mathrm{ZnO}$ powder. The distance between the target and the substrate was $\sim 3 \mathrm{~cm}$ during deposition of VAZO nanorods. Figure 7 represents the pulse laser deposition (PLD) setup used for synthesis of vertically aligned $\mathrm{ZnO}$ nanorods. The substrates used were $n$-doped $400 \mu \mathrm{m} \mathrm{Si} \mathrm{(111)}$ purchased from Siltronic $\mathrm{Ag}$, ITO coated on glass and $\mathrm{Al}_{2} \mathrm{O}_{3}$ substrates purchased from Aldrich (St. Louis, MO, USA). The chamber was maintained at high pressure, 0.3 mbar of oxygen gas throughout the deposition and the growth temperature was changed in between $500{ }^{\circ} \mathrm{C}$ and $600{ }^{\circ} \mathrm{C}$. After the completion of the deposition, the VAZO nanorod samples were cooled down in the same chamber pressure as maintained before. Annealing studies of VAZO nanorods has been done in oxygen and forming gas $\left(95 \% \mathrm{Ar}\right.$ and $\left.5 \% \mathrm{H}_{2}\right)$ atmospheres at a pressure of $0.3 \mathrm{mbar}$ and a temperature of $500{ }^{\circ} \mathrm{C}$ for $30 \mathrm{~min}$. FEI Quanta $200 \mathrm{~S}$ field emission secondary electron microscope (FESEM, Waltham, MA, USA) was used to collect high resolution images of VAZO nanorods. As the nanorods were vertically aligned, it was difficult to collect the images under normal operating conditions. Better quality images were obtained by tilting the specimen stage at an angle of $60^{\circ}$. The diameter and length of the VAZO nanorods were obtained using FESEM images through ImageJ software. We used Bruker D8 Discover X-ray diffractometer (Woodlands, TX, USA) coupled with a Cu K $\alpha$ emission source $(\lambda=1.518 \AA$ ) to investigate the crystal structure of the VAZO nanorods. Operating current and voltage was maintained at $40 \mathrm{~mA}$ and $40 \mathrm{KV}$, respectively, during the XRD measurements. The $2 \theta$ value was maintained in the range between $20^{\circ}$ and $80^{\circ}$. We used a Horiba Labram PL-Raman system (Irvine, CA, USA) for the Raman and photoluminescence (PL) measurements on the VAZO nanorods. A green laser with a wavelength of $532 \mathrm{~nm}$ was used to perform Raman spectroscopy on the as grown VAZO nanorods. Calibration was performed with a standard Si sample prior to all the measurements. PL spectroscopy was performed by using a $325 \mathrm{~nm}$ wavelength laser source. Peak fitting and analysis of the Raman and PL spectra were conducted by using Labspec 5 software.

\section{Conclusions}

VAZO nanorods on Si substrate have been fabricated by a catalyst free high pressure PLD technique. Effects of the substrate type, growth temperature and number of pulsed laser shots have been studied to analyze the crystalline properties of the VAZO nanorods. Factors responsible for alignment of $\mathrm{ZnO}$ nanorods have been investigated, which mainly depend on growth parameters. Temperature and number of pulsed laser shots during the deposition play key roles in the alignment of the $\mathrm{ZnO}$ rods, which was verified from the $\mathrm{E}_{2}$ high mode of VAZO nanorod structures. A way to tune the defect levels is established by changing the diameter of the nanorods, which was performed by changing the growth temperature. Changes in the UV band emissions have been achieved by increasing the number of pulsed laser shots. Annealing studies helped in analyzing defect levels with the help of PL spectroscopy. PL spectroscopy also helped to interpret the reasons behind the observed decrease in defect levels and shift in Raman modes of annealed VAZO nanorod samples. In a nutshell, this research on VAZO nanorods would be helpful for fabrication of optoelectronic devices with improved efficiency.

Acknowledgments: We would like to acknowledge Anagh Bhaumik for his technical support in collecting the SEM images. This Research work is supported by the National Science foundation.

Author Contributions: Priyanka Karnati designed the study, conducted analysis on the topic, and formatted and wrote the entire manuscript. Ariful Haque contributed in designing and editing the manuscript. M. F. N. Taufique contributed to the research with his inputs. Kartik Ghosh provided theoretical guidance and supervised the entire project. 
Conflicts of Interest: The authors declare no conflict of interest.

\section{References}

1. Klinghirn, C. ZnO: Material, physics and applications. J. Chem. Phys. Phys. Chem. 2007, 8, 782-803. [CrossRef] [PubMed]

2. Bhaumik, A.; Haque, A.; Karnati, P.; Taufique, M.F.N.; Patel, R.; Ghosh, K. Copper oxide based nanostructures for improved solar cell efficiency. Thin Solid Films 2014, 572, 126-133. [CrossRef]

3. Willander, M.; Nur, O.; Zhao, Q.X.; Yang, L.L.; Lorenz, M.; Cao, B.Q.; Zuinga Perez, J.; Czekalla, C.; Zimmermann, G.; Grundmann, M.; et al. Zinc oxide nanorod based photonic devices: Recent progress in growth, light emitting diodes and lasers. Nanotechnology 2009, 20, 332001. [CrossRef] [PubMed]

4. Wu, M.; Sun, D.; Tian, C.; Tian, X.; Huang, Y. Al-Doped ZnO Monolayer as a Promising Transparent Electrode Material: A First-Principles Study. Materials 2017, 10, 359. [CrossRef] [PubMed]

5. Antonino, S.A.; Peter, B.; Bruno, S.; Jean, M.T.; Walter, V.S. Nanostructured materials for advanced energy conversion and storage devices. Nat. Mater. 2005, 4, 366-377. [CrossRef]

6. Lukas, S.M.; Judith, L.M.D. ZnO-Nanostructures, defects, and devices. Mater. Today 2007, 10, 40-48. [CrossRef]

7. Morkoc, H.; Ozgur, M. General Properties of ZnO. In Zinc Oxide: Fundamentals, Materials and Device Technology; Wiley-VCH Verlag Gmbh and Co.KGaA: San Francisco, CA, USA, 2009; pp. 1-76; ISBN 9783527623945.

8. Irene, G.V.; Monica, L.C. Vertically-aligned nanostructures of $\mathrm{ZnO}$ for excitonic solar cells: A review. Energy Environ. Sci. 2009, 2, 19-34. [CrossRef]

9. Jae, Y.P.; Sun, W.C.; Sang, S.K. Fabrication of a Highly Sensitive Chemical Sensor Based on ZnO Nanorod Arrays. Nanoscale Res. Lett. 2009, 5, 353. [CrossRef]

10. Wu, J.J.; Liu, S.C. Low-Temperature Growth of Well-Aligned ZnO Nanorods by Chemical Vapor Deposition. Adv. Mater. 2002, 14, 215-218. [CrossRef]

11. Liu, Z.W.; Ong, C.K.; Yu, T.; Shen, Z.X. Catalyst-free pulsed-laser-deposited ZnO nanorods and their room temperature photoluminescence properties. Appl. Phys. Lett. 2006, 88, 053110. [CrossRef]

12. Liu, Z.W.; Ong, C.K. Synthesis and size control of $\mathrm{ZnO}$ nanorods by conventional pulsed-laser deposition without catalyst. Mater. Lett. 2007, 61, 3329-3333. [CrossRef]

13. Hartanto, A.B.; Ning, X.; Nakata, Y.; Okada, T. Growth mechanism of ZnO nanorods from nanoparticles formed in a laser ablation plume. Appl. Phys. A Mater. Sci. Process. 2004, 78, 299-301. [CrossRef]

14. Robert, E. Pulsed Laser Deposition of Thin Films: Applications-Led Growth of Functional Materials; John Wiley and Sons, Inc.: Hoboken, NJ, USA, 2007; p. 75; ISBN 978-0-471-44709-2.

15. Ye, Z.; Hongbo, J.; Rongming, W.; Chinping, C.; Xuhui, L.; Dapeng, Y. Low-temperature growth and Raman scattering study of vertically aligned $\mathrm{ZnO}$ nanowires on Si substrate. Appl. Phys. Lett. 2003, 83, 4631-4633. [CrossRef]

16. Hong, J.F.; Peter, W.; Margit, Z. Semiconductor Nanowires: From Self-Organization to Patterned Growth. Small 2006, 2, 700-717. [CrossRef]

17. Meyer, B.; Dominik, M. Density-functional study of the structure and stability of ZnO surfaces. Phys. Rev. B 2003, 67, 0399002. [CrossRef]

18. Robert, R.R. Lattice parameters of ZnO from $4.2^{\circ}$ to $296^{\circ}$ K. J. Appl. Phys. 1970, 41, 5063-5066. [CrossRef]

19. Arguello, C.A.; Rousseau, D.L.; Porto, S.P.S. First-Order Raman Effect in Wurtzite-Type Crystals. Phys. Rev. 1969, 181, 1351. [CrossRef]

20. Khan, A.A.; Fonobeov, V.A.; Ballndin, A.A. Origin of the optical phonon frequency shifts in $\mathrm{ZnO}$ quantum dots. Appl. Phys. Lett. 2005, 86, 053103. [CrossRef]

21. Mitra, S.S.; Brafman, O.; Daniels, W.B.; Crawford, R.K. Pressure-Induced Phonon Frequency Shifts Measured by Raman Scattering. Phys. Rev. B 1969, 186, 942. [CrossRef]

22. Cheng, A.J.; Tzeng, Y.; Xu, H.; Alur, S.; Wang, Y.; Park, M.; Wu, T.H.; Shannon, C.; Kim, D.-J.; Wang, D. Raman analysis of longitudinal optical phonon-plasmon coupled modes of aligned ZnO nanorods. J. Appl. Phys. 2009, 105, 073104. [CrossRef]

23. Frederic, D.; Julio, P.P.; Macro, A.S.; Jean, C.C.; Alain, P. High-pressure Raman spectroscopy study of wurtzite ZnO. Phys. Rev. B 2002, 65, 092101. [CrossRef] 
24. Lin, B.; Fu, Z.; Jia, Y. Green luminescent center in undoped zinc oxide films deposited on silicon Substrates. Appl. Phys. Lett. 2001, 79, 943-945. [CrossRef]

25. Yao, B.D.; Chan, Y.F.; Wang, N. Formation of ZnO nanostructures by a simple way of thermal evaporation. Appl. Phys. Lett. 2002, 81, 757-759. [CrossRef]

26. Studeikin, S.A.; Gologeo, N.; Cocivera, M. Fabrication of green and orange photoluminescent, undoped ZnO films using spray pyrolysis. J. Appl. Phys. 1998, 84, 2287-2294. [CrossRef]

27. Wu, X.L.; Siu, G.G.; Fu, C.L.; Ong, H.C. Photoluminescence and cathodoluminescence studies of stoichiometric and oxygen-deficient ZnO films. Appl. Phys. Lett. 2001, 78, 2285-2287. [CrossRef]

28. Koida, T.; Chichibu, S.F.; Uedono, A.; Sota, T.; Tsukazki, A.; Kawasaki, M. Radiative and nonradiative excitonic transitions in nonpolar (1120) and polar (0001) and (0001) ZnO epilayers. Appl. Phys. Lett. 2004, 84, 1079-1081. [CrossRef]

29. Lin, C.-Y.; Chen, H.-P.; Liao, H.-C.; Chen, S.-Y. Enhanced luminescent and electrical properties of hydrogen-plasma $\mathrm{ZnO}$ nanorods grown on wafer-scale flexible substrates. Appl. Phys. Lett. 2005, 86, 183103. [CrossRef]

30. Vanheusden, K.; Seager, C.H.; Warren, W.L.; Tallant, D.R.; Vigot, J.A. Correlation between photoluminescence and oxygen vacancies in ZnO phosphors. Appl. Phys. Lett. 1996, 68, 403-405. [CrossRef]

31. Zhao, Q.; Cai, T.; Wang, S.; Zhu, R.; Liao, Z.; Yu, D. Enhanced near-band-edge emission and field emission properties from plasma treated $\mathrm{ZnO}$ nanowires. Appl. Phys. A 2010, 100, 165-170. [CrossRef]

32. Cai, J.W.; Xu, J.P.; Zhang, X.S.; Niu, X.P.; Xing, T.Y.; Ji, T.; Li, L. Defect-related visible luminescence of ZnO nanorods annealed in oxygen ambient. Optoelectron. Lett. 2012, 8, 4-8. [CrossRef]

(C) 2018 by the authors. Licensee MDPI, Basel, Switzerland. This article is an open access article distributed under the terms and conditions of the Creative Commons Attribution (CC BY) license (http:// creativecommons.org/licenses/by/4.0/). 